\title{
MRI findings in a patient with partial monosomy $10 \mathrm{p}$
}

\author{
Fay Sunada, Francis C Rash, David A Tam
}

\begin{abstract}
Partial monosomy $10 p$ is a rare chromosomal disorder charaterised by frontal bossing, micrognathia, congenital heart defects, vesicoureteral abnormalities, and developmental delay. This is the first report to describe seizures not associated with hypocalcaemia, as well as cortical atrophy and decreased white matter volume on magnetic resonance imaging, in a patient with documented partial monosomy 10p. The neuroradiographic abnormalities found in this patient provide a first step towards understanding the aetiology of the developmental delay and ventriculomegaly associated with this chromosomal abnormality.

(F Med Genet 1998;35:159-161)
\end{abstract}

Keywords: partial monosomy 10p; MRI findings

Since the initial description of an infant with partial monosomy 10p by Elliott et al in 1970, at least 25 other cases have been published. ${ }^{1-4}$ Frontal bossing, micrognathia, congenital heart defects, vesicoureteral abnormalities, and developmental delay are found in a significant number of patients with this chromosomal abnormality. ${ }^{5}$ Seizures have been reported in a few patients who also exhibited a concomitant hypocalcaemia. ${ }^{4}$ We present a patient with a partial monosomy 10p, who developed seizures without hypocalcaemia, as well as her findings on magnetic resonance imaging (MRI). Investigation, Naval Medical Center, San Diego, California, USA F Sunada

F C Rash

D A Tam

\section{The Uniformed}

Services University of

the Health Sciences,

Bethesda, Maryland,

USA

F C Rash

D A Tam

Division of Child Neurology, University of California, San Diego, California, USA D A Tam

Correspondence to: Dr Tam, Clinical

Investigation Department, Naval Medical Center, 34800 Bob Wilson Drive, San Diego, CA 92134-5000, USA.

Received 18 September 1996 Revised version accepted for publication 14 August 1997 somal analysis was performed because of the constellation of dysmorphic features and showed a deletion of the short arm of chromo- some $10(\operatorname{del}(10)($ pter $\rightarrow$ p13)). The parents' chromosomes were normal.

At 4 months of age, the patient was admitted to the paediatric intensive care unit with Klebsiella pneumoniae urosepsis, acute tubular necrosis, and respiratory failure. During the latter part of her stay in hospital, she exhibited possible seizure activity and an electroencephalogram (EEG) was performed, showing spike discharges in the right central areas. Serum calcium levels were $9.0 \mathrm{mg} / \mathrm{dl}$ (normal 8.2-11.7 $\mathrm{mg} / \mathrm{dl}$ ). Since no further clinical seizure activity was observed, no treatment was prescribed at that time. A head CT scan showed benign extra-axial fluid collection. Urinary tract evaluation showed bilateral grade II vesicoureteral reflux, multiple diverticula in the left midureter, and bilateral pyelotubular reflux. Quantitative serum immunoglobulins showed IgA $84.8 \mathrm{mg} / \mathrm{dl}$ (normal 78-312), IgM $230 \mathrm{mg} / \mathrm{dl}$ (40-345), IgG $1140 \mathrm{mg} / \mathrm{dl}$ (639-1349), and $\mathrm{IgE} 1 \mathrm{IU} / \mathrm{ml}$ (1-18). $\mathrm{T}$ cell function was not evaluated.

Following discharge, the patient was noted to have poor muscle tone and exhibited delays in gross and fine motor development. She also had delayed speech development. Echocardiogram showed moderate tricuspid regurgitation, mild pulmonary insufficiency, and a patent foramen ovale. At 20 months of age, she was admitted to hospital for Escherichia coli urosepsis. Her height, weight, and head circumference were all at the 10th centile for her chronological age. During her stay in hospital, the patient exhibited activity clinically consistent with seizures. The serum calcium was again normal at $8.2 \mathrm{mg} / \mathrm{dl}$. Although the EEG showed no abnormalities, the patient continued to have recurrent seizure events and valproic acid was empirically started, resulting in the resolution of seizure activity.

The patient underwent magnetic resonance imaging (MRI) of the brain for further evaluation of her seizures, which showed frontal lobe atrophy as a result of decreased white matter volume (fig 1). This was associated with enlargement of the ventricles bilaterally. Furthermore, the left hippocampal gyrus was small and effaced, with resulting dilatation of the left frontal horn. There was no evidence of neuronal migrational abnormalities or other cortical dysplasia.

The patient remained on anticonvulsant therapy and exhibited global developmental delay. She underwent corrective vesicoureteral surgery in order to prevent further episodes of urosepsis. 

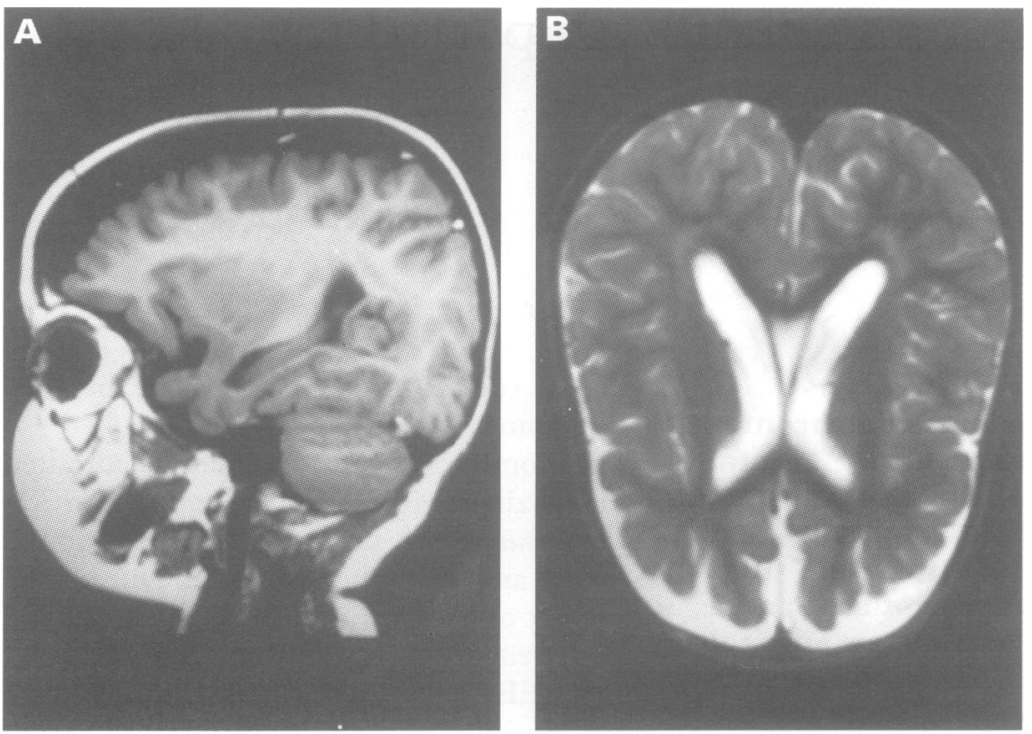

Figure 1 Sagittal T1 weighted (A) and axial T2 weighted (B) MRI shows frontal lobe atrophy as a result of decreased white matter volume.

\section{Discussion}

Approximately 25 patients have been reported with a partial deletion of the short arm of chromosome $10 .{ }^{13-10}$ Although the clinical presentation of this chromosomal abnormality is heterogeneous, a pattern of various findings is becoming apparent. Patients with partial monosomy $10 \mathrm{p}$ manifest a constellation of findings, including psychomotor and growth retardation, craniofacial anomalies, malformations of the trunk, ${ }^{2}$ and features associated with the DiGeorge anomaly. ${ }^{11}$ Patients with velocardiofacial syndromes have also been reported to have partial deletions of $10 \mathrm{p} .^{12}$

Greenberg et $a l^{11}$ reported a patient with partial deletion of the short arm of chromosome 10 with low serum calcium resulting in seizures. " This patient was shown to have hypoparathyroidism, as well as abnormalities of $T$ cell subsets. They suggested that some cases of DiGeorge syndrome may be the result of partial monosomy of $10 \mathrm{p}$. Other authors have subsequently reported the DiGeorge syndrome in patients with this chromosomal anomaly. ${ }^{12} 13$

The patient presented in this report exhibited many of the findings previously described, including micrognathia, downward slanting palpebral fissures, vesicoureteral anomalies, and psychomotor retardation. Her birth weight was appropriate for her gestational age, but she was born seven weeks prematurely. Previous reports have not clearly described abnormalities of gestational age as a finding in patients with partial monosomy $10 \mathrm{p}$.

The patient underwent evaluation as a result of seizure activity. Seizures have been reported in two other patients with deletion of the short arm of chromosome 10. ${ }^{11}$ However, these patients manifested seizure activity with hypocalcaemia, which has been described in partial monosomy $10 \mathrm{p}$ in previous reports. ${ }^{13}$ Our patient had normal serum calcium when she had seizures and also had abnormalities on EEG. Seizures have been reported with increased frequency in children with other chromosomal abnormalities, including mosaic 5p tetrasomy, trisomy 17 mosaicism, and $8 \mathrm{p} 23.1$ deletion. ${ }^{14-16}$ Sgro et $a l^{17}$ studied four patients with $4 \mathrm{p}$ - syndrome and observed a stereotypic EEG pattern characterised by centroparietal or parietotemporal sharp waves, high voltage wave with a superimposed spike, and bursts of diffuse spike and waves. ${ }^{17}$ The patient presented in this report also had right central spike discharges. As more children with partial monosomy $10 \mathrm{p}$ are identified, seizures not resulting from hypocalcaemia may become more recognised as an associated finding.

This is the first reported patient with partial monosomy $10 p$ to have undergone MRI evaluation. Neuropathological studies of three patients with partial monosomy $10 \mathrm{p}$ have shown olfactory bulb, cerebellar, or midbrain hypoplasia, as well as ventricular dilatation. ${ }^{15618}$ No neuroradiographic studies of patients with chromosome $10 p$ deletions have previously been described. Cortical atrophy, as a result of decreased white matter volume, resulted in ventriculomegaly. Ventriculomegaly has been previously described in several patients following neuropathological studies, but a decrease in white matter volume as a proposed aetiology for this finding is new. This decrease in white matter volume may also play an important role in the neurodevelopmental delay seen in the majority of patients. As more patients with partial monosomy $10 \mathrm{p}$ are identified, MRI evaluation may play an increasingly important role in determining the presence of white matter abnormality and resultant cortical atrophy. Furthermore, as MRI is increasingly used as an investigatory tool in cases of developmental delay, the identification of such neuroradiographic findings in patients who manifest other features consistent with $10 \mathrm{p}$ - deletion should prompt chromosomal evaluation.

The Chief, Navy Bureau of Medicine and Surgery, Washington, DC, Clinical Investigation Program sponsored this report $\mathrm{N}$ 84-16-1968-605, as required by HSETCINST $6000.41 \mathrm{~A}$. Th views expressed in this article are those of the authors and do not reflect the official policy or position of the Department of the Navy, Department of Defense, nor the United State Government.

1 Elliott D, Thomas GH, Condron CJ, et al. C-group chromosome abnormality (?10p-). Occurrence in a child with multiple malformations. Am $\mathcal{F}$ Dis Child 1970;119:72 3.

2 Hon E, Chapman C, Gunn TR. Family with partial monosomy 10p and trisomy 10p. Am $\mathcal{F}$ Med Genet 1995;56:136 40.

3 Park JP, McDermet MK, Moeschler JB, Wurster-Hill DH. A case of de novo translocation 7;10 and the duplication $7 \mathrm{p}$ deletion 10p phenotype. Ann Genet 1993;36:217-20.

4 Obregon MG, Mingarelli R, Giannotti A, et al. Partial deletion 10p syndrome. Ann Genet 1992;35:101-4.

Elstner CL, Carey JC, Livingston G, et al. Further delinea tion of the $10 \mathrm{p}$ sydrome. Pediatrics 1984;73:670-5.

6 Berger R, Larroche JC, Toubas PL. Deletion of the short arm of chromosome 10. Acta Paediatr Scand 1977;66:65962 .

7 Bourrouillou G, Colombies P, Gallegos D, et al. Monosomie partielle du bras court d'un chromosome 10: a propos partielle du bras court d'un chromosome 10: a propos Genet 1981;24:61-4.

8 Francke U, Kernahan C, Bradshaw C. Del(10p) autosomal deletion syndrome: clinical, cytologenetic, and gene marke studies. Hum Genet 1975;26:343-51

9 Gencik A, Bronniman U, Tobler R. Partial monosomy of chromosome 10 short arms. $\mathcal{F}$ Med Genet 1983;20:107-11.

10 Klep-de-Pater JM, Bijlsma JB, Alekma FMJ. Partial monosomy 10p syndrome. Eur f Pediatr 1981;137:243-6.

11 Greenberg F, Valdes C, Rosenblatt HM, et al. Hypoparathyroidism and $\mathrm{T}$ cell immune defect in a patient with $10 \mathrm{p}$ deletion syndrome. $\mathcal{f}$ Pediatr 1986;109:489-92. 
12 Daw S, Taylor C, Kraman M, et al. A common region of $10 \mathrm{p}$ deleted in DiGeorge and velocardiofacial syndromes. Nat Genet 1996;13:458-60.

13 Schuffenhauer S, Seidel H, Oechsler H, et al. DiGeorge syndrome and partial monosomy 10p: case report and review. Ann Genet 1995;38:162-7.

14 Stanley W, Powell C, Devine G, et al. Mosaic 5p tetrasomy Am F Med Genet 1993;45:774-6.

15 Shaffer L, McCaskill C, Hersh J, et al. A clinical and molecular study of mosaicism for trisomy 17. Hum Gene 1996;97:69-72.
16 Pettenati $M$, Rao N, Johnson $C$, et al. Molecular cytogenetic analysis of a familial 8 p23.1 deletion associated with minimal dysmorphic features, seizures, and mild menta retardation. Hum Genet 1992;89:602-6.

17 Sgro V, Riva E, Canevini $M$, et al. 4p(-) syndrome: chromosomal disorder associated with a particular EEG pattern. Epilepsia 1995;36:1206-14.

18 Shokeir MHK, Ray M, Hamerton JL, et al. Deletion of the short arm of chromosome no 10. $\mathcal{F}$ Med Genet 1975;12:99113 